\title{
Comparison of clinical and anatomical criteria for resuscitative endovascular balloon occlusion of the aorta (REBOA) among major trauma patients in Nova Scotia
}

\author{
Sean Hurley ${ }^{1} \cdot$ Mete Erdogan $^{2} \cdot$ Nelofar Kureshi $^{3} \cdot$ Patrick Casey $^{4} \cdot$ Matthew Smith $^{4} \cdot$ Robert S. Green $^{1,2,5}$
}

Received: 3 April 2020 / Accepted: 5 February 2021 / Published online: 22 March 2021

(c) The Author(s), under exclusive licence to Canadian Association of Emergency Physicians (CAEP)/ Association Canadienne de Médecine d'Urgence (ACMU) 2021

\begin{abstract}
Objectives To perform a province-wide evaluation of adult major traumas and determine the proportion of patients who met clinical and/or anatomical criteria for resuscitative endovascular balloon occlusion of the aorta (REBOA).

Methods This is a retrospective analysis of all major trauma patients (age $>16$ ) presenting to the sole adult level 1 trauma centre in Nova Scotia over a 5-year period (2012-2017). Data were collected from the Nova Scotia Trauma Registry and medical charts. We identified potential REBOA candidates using either: (1) clinical criteria (primary survey, Focused Assessment with Sonography for Trauma, pelvic/chest X-ray); or (2) anatomical criteria (ICD-10-CA codes). Potential candidates with persistent hypotension were considered true REBOA candidates.

Results Overall 2885 patients were included in the analysis, of whom 248 (8.6\%) patients were in shock (including 106 transfer patients) and had their charts reviewed. A total of 137 patients met clinical criteria for REBOA; 44 (1.5\%) had persistent hypotension 10-20 min into resuscitation and were considered true REBOA candidates. There were 59 patients who met anatomical criteria for REBOA, of whom $15(0.5 \%)$ patients had persistent hypotension and were true REBOA candidates. The 15 REBOA candidates based on anatomical criteria also met clinical criteria for REBOA.

Conclusions In this registry-based retrospective analysis, $1.5 \%$ of adult major trauma patients Nova Scotia were REBOA candidates based on resuscitative clinical presentation, while $0.5 \%$ were candidates based on post hoc anatomical injury patterns. Our findings suggest that using clinical findings and bedside imaging modalities as criteria may overestimate the number of candidates for REBOA.
\end{abstract}

Keywords Trauma $\cdot$ REBOA $\cdot$ Criteria

\section{Résumé}

Objectifs Effectuer une évaluation à l'échelle de la province des traumatismes majeurs chez l'adulte et déterminer la proportion de patients qui répondaient aux critères cliniques et/ou anatomiques de l'occlusion endovasculaire par ballonnet de réanimation de l'aorte (REBOA).

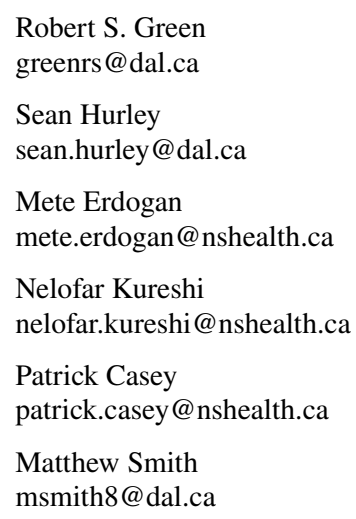

1 Department of Emergency Medicine, Dalhousie University, Halifax, NS B3H 4R2, Canada

2 Trauma Nova Scotia, Nova Scotia Health Authority, Room 1-026B Centennial Building, 1276 South Park Street, Halifax, NS B3H 2Y9, Canada

3 Division of Neurosurgery, Department of Surgery, Dalhousie University, 1796 Summer Street, Halifax, NS B3H 3A7, Canada

4 Division of Vascular Surgery, Department of Surgery, Dalhousie University, 1796 Summer Street, Halifax, NS B3H 3A7, Canada

5 Department of Critical Care, Dalhousie University, Halifax, NS B3H 4R2, Canada 
Les méthodes Analyse rétrospective de tous les patients ayant subi un traumatisme majeur (âge $>16$ ans) qui se sont présentés au seul centre de traumatologie de niveau 1 pour adultes en Nouvelle-Écosse sur une période de 5 ans (2012-2017). Les données ont été recueillies à partir du registre des traumatismes de la Nouvelle-Écosse et des dossiers médicaux. Nous avons identifié des candidats potentiels à la REBOA en utilisant l'un ou l'autre : 1) des critères cliniques (enquête primaire, évaluation ciblée avec échographie pour les traumatismes, radiographie pelvienne/du thorax) ; ou 2) des critères anatomiques (codes CIM-10-CA). Les candidats potentiels présentant une hypotension persistante étaient considérés comme de véritables candidats au REBOA.

Résultats Au total, 2885 patients ont été inclus dans l'analyse, dont 248 (8,6\%) étaient en état de choc (dont 106 patients transférés) et ont vu leur dossier révisé. Au total, 137 patients répondaient aux critères cliniques pour la REBOA ; 44 (1,5 $\%$ ) présentaient une hypotension persistante de 10 à 20 minutes en réanimation et étaient considérés comme de véritables candidats à la REBOA. Il y avait 59 patients qui répondaient aux critères anatomiques pour le REBOA, dont $15(0,5 \%)$ avaient une hypotension persistante et étaient de véritables candidats au REBOA. Les 15 candidats REBOA basés sur des critères anatomiques répondaient également aux critères cliniques de REBOA.

Conclusions Dans cette analyse rétrospective basée sur un registre, $1,5 \%$ des patients adultes ayant subi un traumatisme majeur en Nouvelle-Écosse étaient des candidats au REBOA sur la base d'une présentation clinique de réanimation, tandis que $0,5 \%$ étaient des candidats sur la base de modèles de blessures anatomiques post-hoc. Nos conclusions suggèrent que l'utilisation des résultats cliniques et des modalités d'imagerie au chevet du patient comme critères peut surestimer le nombre de candidats à la REBOA.

\section{Clinician's capsule}

What is known about the topic?

Resuscitative endovascular balloon occlusion of the aorta (REBOA) is a potentially life-saving intervention in trauma patients with non-compressible subdiaphragmatic haemorrhage.

What did this study ask?

Retrospectively, how many patients met criteria for potential REBOA intervention over 5 years at a Canadian Level 1 trauma centre?

What did this study find?

$1.5 \%$ of major trauma patients met clinical criteria for REBOA, while $0.5 \%$ of patients met post hoc anatomical criteria for REBOA.

Why does this study matter to clinicians?

This represents the first evaluation of potential clinical utilization of REBOA in Canada; using clinical criteria may overestimate REBOA candidacy.

\section{Introduction}

Trauma is the leading cause of death in Canada for individuals aged 1-44 years [1] and the leading cause of death and disability worldwide in patients under 60 [2]. Haemorrhage is the second leading cause of traumatic deaths [3] and is responsible for up to $85 \%$ of all treatable traumatic deaths [4]. Non-compressible sub-diaphragmatic haemorrhage is often difficult to diagnose and manage [5] Resuscitative endovascular balloon occlusion of the aorta (REBOA) is a temporizing procedure for haemodynamically unstable patients with suspected sub-diaphragmatic haemorrhage prior to definitive surgical management or angiography.

Despite mixed evidence supporting REBOA use [6-9], trauma centres continue to implement REBOA programs [10]. Two previous studies quantified potential candidates in civilian populations and found $0.5 \%$ and $0.6 \%$ of trauma patients met REBOA criteria in the UK and Philadelphia, respectively $[11,12]$. Both studies retrospectively determined REBOA candidacy based on anatomical injury patterns from definitive imaging, operative reports and autopsies, which may not be obvious at presentation when REBOA is considered. To date, no study has used clinical criteria such as presenting physiology and clinical findings (e.g., primary survey, bedside imaging) to quantify REBOA candidacy. Furthermore, REBOA candidacy has not been evaluated in a Canadian trauma system, where injury patterns differ and transport times may be prolonged [13, 14].

Our primary objective was to determine the proportion of adult major trauma patients in Nova Scotia who met clinical and/or anatomical criteria for REBOA. As secondary objectives, we compared characteristics and outcomes between patients who met clinical and/or anatomical criteria.

\section{Methods}

\section{Study design and setting}

This is a retrospective observational study of all adult major trauma patients presenting to the ED at the Queen Elizabeth II Health Sciences Centre (QEII HSC) over a 5-year period (2012-2017). The QEII HSC is the only adult level 
1 trauma centre in Nova Scotia (population 971,395) and receives some major trauma patients from New Brunswick and Prince Edward Island. The rate of penetrating trauma is around $10 \%$, with approximately $400-450$ adult trauma team activations annually, based on physiologic, anatomic, mechanistic, and logistic criteria [15]. Major trauma patients transported direct from scene to the QEII HSC have a median prehospital time of $51 \mathrm{~min}$ (interquartile range 37.0-71.3 min) [16]. There is currently no REBOA program at our centre.

This study was performed in accordance with the Strengthening the Reporting of Observational Studies in Epidemiology (STROBE) guidelines for reporting observational studies [17]. Ethics approval was obtained from the Nova Scotia Health Authority Research Ethics Board (File\#: 1024562).

\section{Data collection}

Data were collected from the Nova Scotia Trauma Registry (NSTR) and patient chart. The NSTR is a provincial population-based registry under the Nova Scotia Department of Health and Wellness and contains data on patients with an Injury Severity Score $\geq 12$ and an appropriate International Statistical Classification of Diseases and Related Health Problems, Tenth Revision, Canada (ICD-10-CA) code. The registry includes penetrating traumas with an ISS $\geq 9$, all trauma team activations regardless of Injury Severity Score, and traumas resulting in death prior to hospital arrival or in the ED. From the NSTR, we collected age, gender, injury date, injury type (blunt, penetrating), ICD-10-CA injury code, trauma team activation, Glasgow Coma Scale score on ED arrival, Injury Severity Score, maximum Abbreviated Injury Score Head score, systolic blood pressure (SBP) on ED arrival, blood transfusion within $24 \mathrm{~h}$ of injury, time from $\mathrm{ED}$ to operating room (OR), requirement for mechanical ventilation, intensive care unit (ICU) and in-hospital length of stay, and mortality (in-hospital, ED, ICU).

A chart review was performed for trauma patients in shock, defined as having SBP $<90 \mathrm{mmHg}$ on ED arrival and/or requiring transfusion of $\geq 1 \mathrm{U}$ of packed red blood cells (pRBCs) at the sending facility, during transport, or in the ED. The primary author (SH) extracted data from charts through review of primary survey and Focused Assessment with Sonography for Trauma (FAST) documentation (standardized written trauma forms and Trauma Team Leader reports), chest and pelvic X-ray reports. Information was collected from the trauma assessment form and Trauma Team Leader dictated report on FAST results and on any thoracic injury or other REBOA contraindications based on physical examination. Additionally, we collected chest X-ray results, pelvic X-ray results, pulseless electrical activity
(PEA) arrest $>10 \mathrm{~min}$ in the ED, and all SBPs recorded in the nursing notes at 10-20 min following ED arrival.

\section{Criteria for identifying REBOA candidates}

Two separate criteria (clinical, anatomical) were used to determine REBOA candidacy. Anatomical criteria involved ICD-10-CA inclusion and exclusion codes (Supplementary Appendix 1) and were based on an earlier study which included four categories: pelvic fractures, solid organ injuries (liver, spleen, kidney, pancreas), traumatic lower extremity amputation, and major abdominal and lower extremity vascular injuries [12]. Patients with major neck vascular injuries, thoracic injuries, axillary injuries, upper extremity with amputation and/or vascular injuries were excluded. Alternatively, clinical criteria were based largely on the Shock Trauma REBOA algorithm which identifies any patient in shock ( $\mathrm{SBP}<90 \mathrm{mmHg}$ ) without obvious thoracic injury on chest X-ray as a REBOA candidate [18]. Zone 1 and zone 3 REBOA placement is differentiated based on FAST and pelvic X-ray interpretation.

When applying clinical criteria, we excluded transfers with prior computed tomography imaging showing no major abdominal or pelvic injuries, which were presumed to be readily available to the Trauma Team Leader before or on ED arrival. In applying clinical or anatomical criteria, we excluded patients who did not meet trauma team activations criteria, had PEA arrest $>10$ min before ED arrival, had emergent laparotomy at a regional hospital prior to transfer, had pre-existing terminal illness, or had contraindicated injuries including major neck vascular trauma, isolated penetrating thoracic trauma, isolated head trauma, suspected neurogenic shock, upper extremity vascular trauma or amputation, lower extremity below knee amputation, burns, drowning, or suspected thoracic aortic injury on portable chest X-ray.

Patients who met all clinical or anatomical inclusion criteria (and no exclusion criteria) were considered "potential" REBOA candidates. Potential candidates with documentation of at least one episode of an SBP $<90 \mathrm{mmHg}$ in the 10-20 min following ED arrival were deemed non-responders or partial responders to initial resuscitation efforts and considered "true" REBOA candidates.

\section{Outcome measures}

Primary outcome of interest was the proportion of true REBOA candidates among all major trauma patients, based on clinical or anatomical criteria. Secondary outcomes included time from ED to OR, requirement for mechanical ventilation, length of stay (in-hospital, ICU), and mortality (in-hospital, ED, ICU). 
Fig. 1 Flowchart of patient selection using clinical or anatomical criteria for REBOA. NSTR Nova Scotia Trauma Registry, $p R B C$ packed red blood cells, EMR electronic medical record, REBOA resuscitative endovascular balloon occlusion of the aorta, L1TC Level 1 Trauma Centre, $C T$ computed tomography, $C X R$ chest X-ray, SBP systolic

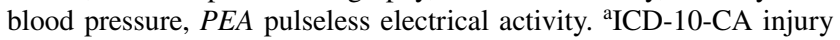
codes for inclusion and exclusion (Supplementary Appendix 1). Patients were excluded if they did not meet trauma team activation criteria, had PEA $>10 \mathrm{~min}$, or had emergent laparotomy at a regional hospital prior to transfer. They were further excluded if they had $\mathrm{SBP}>90 \mathrm{mmHg}$ at $10-20 \mathrm{~min}$ into resuscitation. ${ }^{\text {b Trauma team }}$ activation, FAST, pelvic X-ray, chest X-ray. Patients were excluded if they did not meet these criteria, or if they had a CT in a regional hospital prior to transfer that did not show intraabdominal or pelvic injuries, emergent laparotomy at a regional hospital prior to transfer, CXR with suspected thoracic aortic injury, or any other clearly documented injury pattern on primary survey not amenable to REBOA. They were further excluded if they had SBP $\geq 90 \mathrm{mmHg}$ at 10-20 min into resuscitation

\section{Data analysis}

Simple descriptive statistics were used to report patient characteristics and outcomes. Students $t$ tests and Chisquare or Fisher's exact test were used, as appropriate, to compare characteristics and outcomes between potential or true REBOA candidates based on: (1) clinical criteria or (2) anatomical criteria. To maintain independence of groups, patients who met both clinical and anatomical criteria were assigned to the anatomical criteria group. All analyses were performed using IBM SPSS Statistics Version 25 (Armonk, NY: IBM Corp). In keeping with the privacy policy of the Nova Scotia Department of Health and Wellness, cell sizes smaller than 5 are reported as " $n<5$ ".

\section{Results}

There were 2885 adult major trauma patients over a 5 -year period (Fig. 1). Of these, $248(8.6 \%)$ patients (including 106 transfers) were in shock (97 had SBP $<90 \mathrm{mmHg}$ on ED arrival, 181 required blood transfusion, and 30 had $\mathrm{SBP}<90 \mathrm{mmHg}$ on ED arrival and required blood transfusion) and underwent a detailed chart review. We identified 137 patients that met clinical criteria for REBOA, of whom 44 (1.5\% overall, $17.7 \%$ of shock patients) had persistent hypotension 10-20 min into resuscitation and were considered true REBOA candidates (39 in zone 1, 5 in zone 3). By comparison, 47 patients with shock met anatomical criteria for REBOA. Of these, $15(0.5 \%$ overall, $6.0 \%$ of shock patients) had persistent hypotension and were deemed true REBOA candidates. All 15 true REBOA candidates based on anatomical criteria also met clinical criteria for REBOA.

Table 1 compares characteristics and outcomes of potential REBOA candidates based on clinical or anatomical criteria. Both sets of criteria were met by 47 patients;

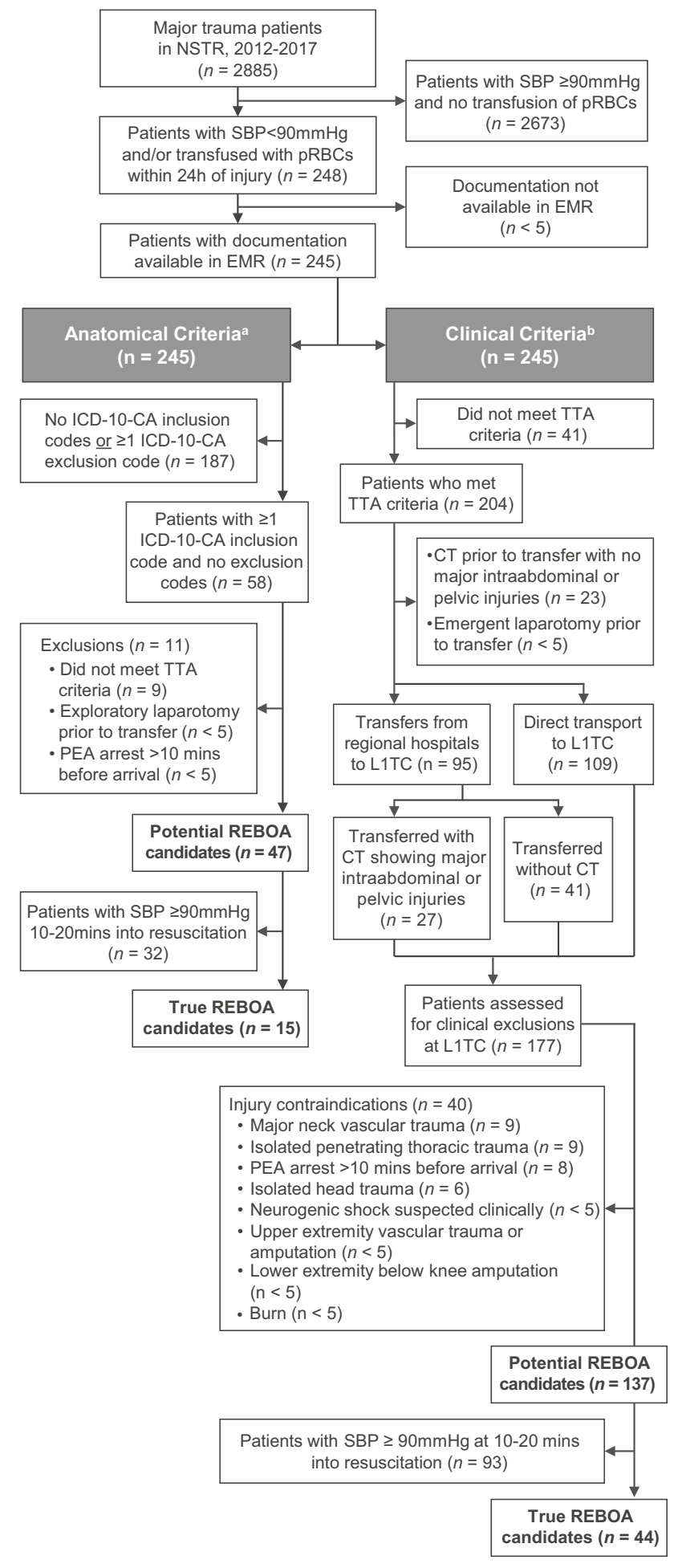

these patients were included in the anatomical criteria group. Patients who met clinical criteria were more likely to have a higher Injury Severity Score $(27.7 \pm 12.4$ vs. $19.2 \pm 10.2 ; p<0.001)$ and higher respiratory rate on ED arrival ( $22.9 \pm 6.9$ breaths/min vs. $20.6 \pm 4.6$ breaths/ $\min ; p=0.042$ ). A greater proportion of patients who met 
anatomical criteria had a mild Glasgow Coma Scale on ED arrival $(66.0 \%$ vs. $42.2 \%$; $p=0.008)$. Both groups were similar in age, gender, injury type, other vitals on arrival (SBP, temperature, heart rate), blood transfusion, time to $\mathrm{OR}$, and transfers. The only difference in outcomes was increased
ICU length of stay in patients who met clinical criteria $(6.7 \pm 7.4$ days vs. $3.0 \pm 5.6$ days; $p=0.003)$.

Characteristics and outcomes of true REBOA candidates are compared in Table 2 . The only difference observed between patients who met clinical or anatomical criteria was increased ISS in those who met clinical criteria $(32.1 \pm 12.0$
Table 1 Characteristics and outcomes of potential REBOA candidates based on clinical or anatomical criteria

\begin{tabular}{|c|c|c|c|}
\hline Characteristic/outcome & Clinical criteria $(n=90)^{\mathrm{a}}$ & Anatomical criteria $(n=47)$ & $p$ value \\
\hline \multicolumn{4}{|l|}{ Characteristics } \\
\hline Age, mean \pm SD (range) & $47.3 \pm 22.0(17-89)$ & $47.3 \pm 19.3(18-83)$ & 1.00 \\
\hline Male gender, $n(\%)$ & $63(70.0)$ & $32(68.1)$ & 0.82 \\
\hline \multicolumn{4}{|l|}{ Injury type, $n(\%)$} \\
\hline Blunt & $81(90.0)$ & $39(83.0)$ & 0.24 \\
\hline Penetrating & $9(10.0)$ & $8(17.0)$ & \\
\hline \multicolumn{4}{|l|}{ GCS on ED arrival, $n(\%)$} \\
\hline Mild (14-15) & $38(42.2)$ & $31(66.0)$ & 0.008 \\
\hline Moderate (9-13) & $6(6.7)$ & $n<5$ & 0.46 \\
\hline Severe (3-8) & $5(5.5)$ & $n<5$ & 0.74 \\
\hline Missing & $41(45.6)$ & $13(27.7)$ & 0.042 \\
\hline \multicolumn{4}{|l|}{ Max AIS head, mean \pm SD } \\
\hline Mild/moderate (1-2) & $21(23.3)$ & $9(19.1)$ & 0.57 \\
\hline Serious/severe (3-4) & $16(17.8)$ & $n<5$ & 0.23 \\
\hline Critical (5) & $12(13.3)$ & $n<5$ & 0.17 \\
\hline Missing & $41(45.6)$ & $32(68.1)$ & 0.012 \\
\hline ISS, mean \pm SD & $27.7 \pm 12.4$ & $19.2 \pm 10.2$ & $<0.001$ \\
\hline \multicolumn{4}{|l|}{ Vitals on ED arrival, mean \pm SD } \\
\hline SBP & $106.6 \pm 30.1$ & $101.1 \pm 31.0$ & 0.32 \\
\hline Temp & $36.4 \pm 1.1$ & $36.3 \pm 1.1$ & 0.61 \\
\hline $\mathrm{RR}$ & $22.9 \pm 6.9$ & $20.6 \pm 4.6$ & 0.042 \\
\hline HR & $101.7 \pm 26.7$ & $99.9 \pm 27.6$ & 0.71 \\
\hline Blood transfusion $^{\mathrm{b}}, n(\%)$ & $77(85.6)$ & $40(85.1)$ & 0.94 \\
\hline \multicolumn{4}{|l|}{ Time to OR } \\
\hline Within $2 \mathrm{~h}, n(\%)$ & $19(21.1)$ & $17(36.2)$ & 0.057 \\
\hline Within $12 \mathrm{~h}, n(\%)$ & $48(53.3)$ & $31(66.0)$ & 0.16 \\
\hline Within 24 h, $n(\%)$ & $55(61.1)$ & $36(76.6)$ & 0.07 \\
\hline Overall, median (in hours) [IQR] & $7.2[2.4-24.6]$ & $3.7[1.4-13.9]$ & 0.26 \\
\hline Transfers, $n(\%)$ & $43(47.8)$ & $22(46.8)$ & 0.91 \\
\hline \multicolumn{4}{|l|}{ Outcomes } \\
\hline \multicolumn{4}{|l|}{ LOS, mean \pm SD } \\
\hline ICU & $6.7 \pm 7.4$ & $3.0 \pm 5.6$ & 0.003 \\
\hline In-hospital & $25.0 \pm 44.6$ & $25.4 \pm 48.6$ & 0.96 \\
\hline Mechanical ventilation, mean \pm SD & $6.4 \pm 7.2$ & $4.1 \pm 5.5$ & 0.06 \\
\hline \multicolumn{4}{|l|}{ Mortality, $n(\%)$} \\
\hline ED & $n<5$ & $0(0)$ & 0.55 \\
\hline ICU & $15(16.7)$ & $6(12.8)$ & 0.55 \\
\hline In-hospital & $21(23.3)$ & $6(12.8)$ & 0.14 \\
\hline
\end{tabular}

$R E B O A$ resuscitative endovascular balloon occlusion of the aorta, ISS Injury Severity Score, AIS Abbreviated Injury Scale, GCS Glasgow Coma Scale, $E D$ emergency department, $I C U$ intensive care unit, $O R$ operating room, $S D$ standard deviation, $I Q R$ interquartile range

${ }^{a}$ Excluding 47 patients who also met anatomical criteria

${ }^{\mathrm{b}}$ Within $24 \mathrm{~h}$ of injury 
vs. $19.0 \pm 10.9 ; p=0.001)$. Outcomes were similar between true REBOA candidates who met clinical or anatomical criteria. Finally, Table 3 describes characteristics of 29 patients who met clinical criteria (but not anatomical criteria) for REBOA.

\section{Discussion}

\section{Interpretation of findings}

This study represents the first assessment of REBOA candidacy in a Canadian provincial trauma system and the first
Table 2 Characteristics and outcomes of true REBOA candidates based on clinical or anatomical criteria

\begin{tabular}{|c|c|c|c|}
\hline Characteristic/outcome & Clinical criteria $(n=29)^{\mathrm{a}}$ & Anatomical criteria $(n=15)$ & $p$ value \\
\hline \multicolumn{4}{|l|}{ Characteristics } \\
\hline Age, mean $\pm \mathrm{SD}$ (range) & $45.1 \pm 21.4(17-87)$ & $47.7 \pm 17.7(18-83)$ & 0.69 \\
\hline Male gender, $n(\%)$ & $23(79.3)$ & $11(70.7)$ & 0.65 \\
\hline Injury type, $n(\%)$ & & & 0.07 \\
\hline Blunt & $27(93.1)$ & $11(73.3)$ & \\
\hline Penetrating & $n<5$ & $n<5$ & \\
\hline \multicolumn{4}{|l|}{ GCS on ED arrival, mean \pm SD } \\
\hline Mild (14-15) & $9(31.0)$ & $8(53.3)$ & 0.15 \\
\hline Moderate (9-13) & $n<5$ & $0(0)$ & 0.34 \\
\hline Severe $(3-8)$ & $n<5$ & $n<5$ & 0.96 \\
\hline Missing & $12(41.4)$ & $5(33.3)$ & 0.60 \\
\hline \multicolumn{4}{|l|}{ Max AIS head, mean \pm SD } \\
\hline Mild/moderate (1-2) & $7(24.1)$ & $n<5$ & 0.76 \\
\hline Serious/severe (3-4) & $n<5$ & $n<5$ & 0.77 \\
\hline Critical (5) & $8(27.6)$ & $n<5$ & 0.22 \\
\hline Missing & $11(37.9)$ & $9(60.0)$ & 0.16 \\
\hline ISS, mean \pm SD & $32.1 \pm 12.0$ & $19.0 \pm 10.9$ & 0.001 \\
\hline \multicolumn{4}{|l|}{ Vitals on ED arrival, mean \pm SD } \\
\hline SBP & $95.3 \pm 36.4$ & $92.7 \pm 44.7$ & 0.84 \\
\hline Temp & $36.3 \pm 1.4$ & $36.1 \pm 0.6$ & 0.60 \\
\hline $\mathrm{RR}$ & $24.2 \pm 6.8$ & $21.0 \pm 5.7$ & 0.13 \\
\hline HR & $101.8 \pm 32.1$ & $84.1 \pm 31.9$ & 0.09 \\
\hline Blood transfusion $^{\mathrm{b}}, n(\%)$ & $22(75.9)$ & $10(66.7)$ & 0.51 \\
\hline \multicolumn{4}{|l|}{ Time to OR } \\
\hline Within $2 \mathrm{~h}, n(\%)$ & $11(37.9)$ & $7(46.7)$ & 0.58 \\
\hline Within $12 \mathrm{~h}, n(\%)$ & $18(62.1)$ & $10(66.7)$ & 0.76 \\
\hline Within $24 \mathrm{~h}, n(\%)$ & $20(69.0)$ & $10(66.7)$ & 0.88 \\
\hline Overall, median in hours [IQR] & $4.3[1.3-18.8]$ & $1.7[0.8-32.1]$ & 0.55 \\
\hline Transfers, $n(\%)$ & $10(34.5)$ & $n<5$ & 0.13 \\
\hline \multicolumn{4}{|l|}{ Outcomes } \\
\hline \multicolumn{4}{|l|}{ LOS, mean \pm SD } \\
\hline ICU & $6.8 \pm 8.5$ & $5.5 \pm 8.4$ & 0.63 \\
\hline In-hospital & $22.5 \pm 29.8$ & $41.7 \pm 82.8$ & 0.27 \\
\hline Mechanical ventilation, mean $\pm S D$ & $6.32 \pm 8.6$ & $5.36 \pm 7.4$ & 0.72 \\
\hline \multicolumn{4}{|l|}{ Mortality, $n(\%)$} \\
\hline ED & $n<5$ & $0(0)$ & 0.54 \\
\hline ICU & $8(27.6)$ & $n<5$ & 1.00 \\
\hline In-hospital & $13(44.8)$ & $n<5$ & 0.24 \\
\hline
\end{tabular}

REBOA resuscitative endovascular balloon occlusion of the aorta, ISS Injury Severity Score, AIS Abbreviated Injury Scale, GCS Glasgow Coma Scale, $E D$ emergency department, $I C U$ intensive care unit, $O R$ operating room, $S D$ standard deviation, $I Q R$ interquartile range

${ }^{a}$ Excluding 15 patients who also met anatomical criteria

${ }^{\mathrm{b}}$ Within $24 \mathrm{~h}$ of injury 
application of clinical criteria to identify REBOA candidates. Over a 5-year period, $1.5 \%$ of major trauma patients were REBOA candidates based on clinical criteria, while $0.5 \%$ were candidates based on anatomical injury patterns. REBOA programs require the involvement of multiple medical and surgical specialties and allied healthcare providers, robust simulation and skills maintenance programs, financial considerations, and commitment to quality assurance and patient safety [19]. Based on the results of this study, only Canadian trauma centres with adequate volumes of critically ill trauma patients are likely to support a robust and viable REBOA program.

\section{Comparison to previous studies}

Two previous studies of REBOA candidacy have been performed in civilian populations; both used anatomical injury patterns from definitive imaging, operative reports, and autopsies as criteria $[11,12]$. Despite differences in geography and rates of penetrating trauma, our study identified a similar percentage $(0.5 \%)$ of REBOA candidates based on anatomical criteria compared to $0.5 \%$ in the UK [11] and $0.6 \%$ in Philadelphia, USA [12]. Definitive imaging, OR reports and autopsies are not readily available when patients present to the ED, which is a limitation of these studies. To overcome this limitation, we assessed REBOA candidacy based on documented physiology on ED arrival, clinical findings, and bedside imaging.

\section{Strengths and limitations}

This study has several limitations. First, there is no clear consensus on the indications for REBOA. Using $\mathrm{SBP}<90 \mathrm{mmHg}$ and/or $1 \mathrm{U}$ of pRBCs in $24 \mathrm{~h}$ as indicators of haemorrhagic shock is debatable. Our decision to use $\mathrm{SBP}<90 \mathrm{mmHg}$ was largely based on the Shock Trauma

Table 3 Injury patterns of true REBOA candidates who met clinical but not anatomical criteria

\begin{tabular}{ll}
\hline Injury pattern & $\begin{array}{l}\text { True REBOA } \\
\text { candidates } \\
(n=29)\end{array}$ \\
\hline No abdominal injury, $n(\%)$ & $9(31.0)$ \\
Isolated intracranial injury & $n<5$ \\
Isolated thoracic injury & $n<5$ \\
Intracranial + thoracic injuries & $n<5$ \\
Spinal cord injury & $n<5$ \\
Other & $n<5$ \\
Abdominal injury with exclusion, $n(\%)$ & $20(69.0)$ \\
Thoracic injury & $18(62.1)$ \\
Neck vessel injury & $n<5$ \\
\hline
\end{tabular}

REBOA, resuscitative endovascular balloon occlusion of the aorta
REBOA algorithm [18], the most widely cited and accepted criteria [20-22]. We included patients who received $\geq 1 \mathrm{U}$ pRBCs within $24 \mathrm{~h}$ to capture patients who potentially had a SBP $\geq 90 \mathrm{mmHg}$ on arrival but quickly decompensated in the ED, as practice in our trauma system utilizes early transfusion for any trauma related hypotension. There is likely a clinical difference between a patient who receives blood products for resuscitation due to haemorrhagic shock on ED arrival versus a haemodynamically stable patient who receives blood products for anaemia $23 \mathrm{~h}$ after ED arrival. The NSTR only captures data on transfusions within $24 \mathrm{~h}$ of injury; however, our initial screening criteria were meant to be oversensitive. Second, in order to differentiate potential and true candidates, we used lowest documented SBP 10-20 min into resuscitation to identify patients in shock that were partial or non-responders to initial resuscitation efforts in a reasonable timeframe to consider placement and inflation of a REBOA catheter. Third, since a single author reviewed the charts, there could be potential discrepancies in the interpretation of chart documentation of the primary survey and Trauma Team Leader clinical reports. Furthermore, while formal reports of portable chest and pelvic X-rays were not readily available at time of initial ED assessment, the identification of obvious major injuries was assumed to be within the skillset of the Trauma Team Leaders. A final limitation unique to our population is the transfer of trauma patients from all regional centres to a single level 1 trauma centre. Some patients who presented to a regional centre could have met clinical criteria for REBOA (e.g., several patients underwent emergency laparotomy prior to transfer to the QEII HSC). However, since there is unlikely to be the patient volume or expertise to insert and manage REBOA catheters in these smaller centres, we screened for REBOA candidacy following patient arrival at the QEII HSC only. Despite these limitations, this study has important strengths. Data were collected from a provincial population-based registry with quality-control procedures for accurate and complete data entry including computer checks, visual checks, and an annual re-abstracting audit of $10 \%$ of cases. Although our results should be generalizable to other trauma systems in Canada, more work is required to validate our findings in other centres.

\section{Clinical implications}

Our study found 15 patients who met both clinical and anatomical criteria for REBOA and a further 29 patients who only met clinical criteria. This suggests applying clinical criteria derived from pre-existing algorithms may overestimate REBOA candidacy when based on clinical findings and bedside imaging modalities alone, and therefore REBOA may be utilized when it is not indicated. Nine of these patients did not have abdominal or pelvic injuries, but 
rather some other injury accounting for their shock presentation (e.g., major intracranial injury, spinal cord injury, or isolated thoracic injury). Placement of REBOA catheters in these patients would expose them to potential harms such as vascular access complications, distal ischaemia, and reperfusion injuries without having any intra-abdominal or pelvic injuries that would benefit from REBOA [23]. The remaining 20 patients had abdominal or pelvic injuries potentially amenable to REBOA, but had other injuries that would have excluded them from REBOA placement including thoracic or neck vascular injuries. Most of these patients were excluded for traumatic haemothorax; REBOA placement distal to injury could lead to increased thoracic haemorrhage, potentially worsening their outcomes.

\section{Research implications}

Although studies have demonstrated REBOA is effective in raising the SBP of patients in major haemorrhagic shock once it is placed in the correct aortic zone, evidence for the mortality benefit following REBOA in patients with traumatic haemorrhage continues to be mixed [24]. Two recent studies used propensity score matching to compare outcomes between patients who underwent REBOA and those who did not and found increased overall mortality [7, 8], and higher rates of acute kidney injury and lower limb amputations in the REBOA group [8]. A third study, however, observed improved survival to discharge among REBOA patients using a nationwide trauma database in Japan [25]. The discrepancy of patient selection between anatomical and clinical criteria may help to explain the discordant outcomes with REBOA in these studies. Our study suggests identifying abdominal or pelvic injuries amenable to REBOA and excluding patients with contraindicated injury patterns is difficult in many critically ill trauma patients. Future work is needed to determine which patients will benefit most from REBOA based on clinical presentation and bedside imaging modalities.

\section{Conclusion}

In this registry-based retrospective analysis, $1.5 \%$ of all adult major trauma patients in Nova Scotia were REBOA candidates based on resuscitative clinical presentation and bedside imaging, while $0.5 \%$ were candidates based on post hoc anatomical injury patterns. Our findings suggest that using clinical findings and bedside imaging modalities as criteria may overestimate the number of candidates for REBOA.

Supplementary Information The online version contains supplementary material available at https://doi.org/10.1007/s43678-021-00100-3.
Acknowledgements The authors thank Karen Ssebazza (Registry Coordinator, TNS) and David Urquhart (IT Manager, Department of Emergency Medicine, Dalhousie University) for assisting with data collection. Data used in this research were made available by the Nova Scotia Department of Health and Wellness. Any opinions expressed by the authors do not necessarily reflect the opinion of the Nova Scotia Department of Health and Wellness or TNS.

Funding This research received no specific grant from any funding agency, commercial or not-for-profit sectors.

\section{Compliance with ethical standards}

Conflict of interest The author(s) declare no competing interests.

\section{References}

1. Statistics Canada. Leading causes of death, total population, by age group (Table: 13-10-0394-01). https://www150.statcan.gc.ca/ t1/tbl1/en/tv.action?pid=1310039401. Accessed 22 Sept 2020.

2. World Health Organization. Disease burden and mortality estimates. https://www.who.int/healthinfo/global_burden_disease/ estimates/en/index1.html. Accessed 18 Sept 2020.

3. Pfeifer R, Teuben M, Andruszkow H, Barkatali BM, Pape H. Mortality patterns in patients with multiple trauma: a systematic review of autopsy studies. PLoS ONE. 2016;11(2):e0148844. https://doi.org/10.1371/journal.pone.0148844.

4. Kauvar DS, Lefering R, Wade CE. Impact of hemorrhage on trauma outcome: an overview of epidemiology, clinical presentations, and therapeutic considerations. J Trauma. 2006;60(6 Suppl):S3-11. https://doi.org/10.1097/01.ta.0000199961.02677. 19.

5. Morrison JJ, Rasmussen TE. Noncompressible torso hemorrhage: a review with contemporary definitions and management strategies. Surg Clin N Am. 2012;92(4):843-58. https://doi.org/10. 1016/j.suc.2012.05.002.

6. Brenner M, Inaba K, Aiolfi A, DuBose J, Fabian T, Bee T, et al. Resuscitative endovascular balloon occlusion of the aorta and resuscitative thoracotomy in select patients with hemorrhagic shock: early results from the American Association for the Surgery of Trauma's aortic occlusion in resuscitation for trauma and acute care surgery registry. J Am Coll Surg. 2018;226(5):730-40. https://doi.org/10.1016/j.jamcollsurg.2018.01.044.

7. Inoue J, Shiraishi A, Yoshiyuki A, Haruta K, Matsui H, Otomo Y. Resuscitative endovascular balloon occlusion of the aorta might be dangerous in patients with severe torso trauma: a propensity score analysis. J Trauma Acute Care Surg. 2016;80(4):557-9. https://doi.org/10.1097/TA.0000000000000968.

8. Joseph B, Zeeshan M, Sakran JV, Hamidi M, Kulvatunyou N, Khan M, et al. Nationwide analysis of resuscitative endovascular balloon occlusion of the aorta in civilian trauma. JAMA Surg. 2019;154(6):500-8. https://doi.org/10.1001/jamasurg.2019.0096.

9. Manzano Nunez R, Naranjo MP, Foianini E, Ferrada P, Rincon E, García-Perdomo HA, et al. A meta-analysis of resuscitative endovascular balloon occlusion of the aorta (REBOA) or open aortic cross-clamping by resuscitative thoracotomy in non-compressible torso hemorrhage patients. World J Emerg Surg. 2017;12:30. https://doi.org/10.1186/s13017-017-0142-5.

10. Bekdache O, Paradis T, Shen YBH, Elbahrawy A, Grushka J, Deckelbaum D, et al. Resuscitative endovascular balloon occlusion of the aorta (REBOA): indications: advantages and challenges of implementation in traumatic non-compressible torso 
hemorrhage. Trauma Surg Acute Care Open. 2019;4(1):e000262. https://doi.org/10.1136/tsaco-2018-000262.

11. Barnard EB, Morrison JJ, Madureira RM, Lendrum R, FragosoIniguez M, Edwards A, et al. Resuscitative endovascular balloon occlusion of the aorta (REBOA): a population based gap analysis of trauma patients in England and Wales. Emerg Med J. 2015;32(12):926-32. https://doi.org/10.1136/emerm ed-2015-205217.

12. Dumas RP, Holena DN, Smith BP, Jafari D, Seamon MJ, Reilly $\mathrm{PM}$, et al. Resuscitative endovascular balloon occlusion of the aorta: assessing need in an urban trauma center. J Surg Res. 2019;233:413-9. https://doi.org/10.1016/j.jss.2018.08.031.

13. Moore L, Stelfox HT, Evans D, Hameed SM, Yanchar NL, Simons $\mathrm{R}$, et al. Trends in injury outcomes across Canadian trauma systems. JAMA Surg. 2017;152(2):168-74. https://doi.org/10.1001/ jamasurg.2016.4212.

14. Tansley G, Schuurman N, Erdogan M, Bowes M, Green R, Asbridge M, et al. Development of a model to quantify the accessibility of a Canadian trauma system. CJEM. 2017;19(4):285-92. https://doi.org/10.1017/cem.2017.9.

15. QEII HSC Trauma Team Activation Criteria. Nova Scotia Trauma Program. 2013. http://www.cdha.nshealth.ca/system/files/sites/ 139/documents/trauma-team-activation-criteria.pdf. Accessed 15 Sept 2020.

16. Rouse C, Hayre J, French J, Fraser J, Watson I, Benjamin S, et al. A traumatic tale of two cities: does EMS level of care and transportation model affect survival in patients with trauma at level 1 trauma centres in two neighbouring Canadian provinces? Emerg Med J. 2018;35:83-8. https://doi.org/10.1136/emerm ed-2016-206329.

17. Von Elm E, Altman DG, Egger M, Pocock SJ, Gotzsche PC, Vandenbroucke JP, STROBE Initiative. Strengthening the Reporting of Observational Studies in Epidemiology (STROBE) statement: guidelines for reporting observational studies. BMJ. 2007;335(7624):806-8.

18. Brenner M, Hoehn M, Pasley J, Dubose J, Stein D, Scalea T. Basic endovascular skills for trauma course: bridging the gap between endovascular techniques and the acute care surgeon. J Trauma Acute Care Surg. 2014;77(2):286-91. https://doi.org/10.1097/TA. 0000000000000310.

19. Qasim Z, Bradley K, Panichelli H, Robinson J, Zern SC. Successful interprofessional approach to development of a resuscitative endovascular balloon occlusion of the aorta program at a community trauma center. J Emerg Med. 2018;54(4):419-26. https:// doi.org/10.1016/j.jemermed.2018.01.005.

20. Brenner M, Hicks C. Major abdominal trauma: critical decisions and new frontiers in management. Emerg Med Clin N Am. 2018;36(1):149-60. https://doi.org/10.1016/j.emc.2017.08.012.

21. Brenner M, Teeter W, Hoehn M, Pasley J, Hu P, Yang S, et al. Use of resuscitative endovascular balloon occlusion of the aorta for proximal aortic control in patients with severe hemorrhage and arrest. JAMA Surg. 2018;153(2):130-5. https://doi.org/10.1001/ jamasurg.2017.354934T.

22. Osborn LA, Brenner ML, Prater SJ, Moore LJ. Resuscitative endovascular balloon occlusion of the aorta: current evidence. Open Access Emerg Med. 2019;2019(11):29-38. https://doi.org/ 10.2147/OAEM.S166087.

23. Ribeiro Junior MAF, Feng CYD, Nguyen ATM, Rodrigues VC, Bechara GEK, de-Moura RR, et al. The complications associated with Resuscitative Endovascular Balloon Occlusion of the Aorta (REBOA). World J Emerg Surg. 2018;13:20. https://doi.org/10. 1186/s13017-018-0181-6.

24. Borger van derBurg BLS, van Dongen TTCF, Morrison JJ, Hedeman Joosten PPA, DuBose JJ, Hörer TM, et al. A systematic review and meta-analysis of the use of resuscitative endovascular balloon occlusion of the aorta in the management of major exsanguination. Eur J Trauma Emerg Surg. 2018;44(4):535-50. https:// doi.org/10.1007/s00068-018-0959-y.

25. Yamamoto R, Cestero RF, Suzuki M, Funabiki T, Sasaki J. Resuscitative endovascular balloon occlusion of the aorta (REBOA) is associated with improved survival in severely injured patients: a propensity score matching analysis. Am J Surg. 2019;218(6):1162-8. https://doi.org/10.1016/j.amjsurg.2019.09. 007. 